\title{
Investigations of harbour brick structures by using operational modal analysis
}

\author{
Mariusz Żółtowski, Ph. D., \\ University of Technology and Life Science in Bydgoszcz, Poland
}

\begin{abstract}

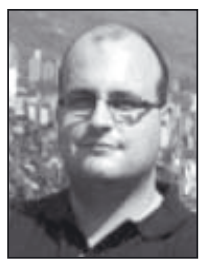

Historic harbour brick objects are subject to large dynamic loads clearly reflected by generated vibration processes. The vibrations may affect state of serviceability of structures by lowering comfort of persons working there as well as possible reaching the level hazardous to safety of the structures. The effect of vibrations to structure is mainly manifested by additional stresses in a given cross-section, which are summed up with those resulting from static loads. Moreover often occur consequences associated with environmental conditions and fatigue of materials which accelerate destruction of the objects. Therefore the dynamic loads may cause damaging effects in buildings of various structural types or even lead to their catastrofic destruction. Judging the necessity of improving the quality assessment methods of building structures for purposes of estimation of their state as well as safety factors for brick structures (see PN-B03002 standard, p.3.1.3 and 4.6), the author of this work undertook an attempt to investigate destruction process of selected building structures by using the method of operational modal analysis.
\end{abstract}

Key words: modal analysis; natural vibration frequency; stabilization diagram; structural vibrations

\section{INTRODUCTION}

Modern building structures, production of silent-running machines and devices are associated with a high precision level of their manufacturing and appropriate selection of materials that greatly influence their quality, reliability and durability $[5,17,21]$.

In investigating real systems (structures, buildings, machines, devices) the main problem is to determine quantity of energy stored, dissipated and transmitted by particular elements of the systems. Knowledge of the quantities serves to assessing material effort, fatigue, diagnostic investigations as well as predicting noise levels, and also to facilitate designing system's elements (e.g. vibration isolation) [3, 10, 15, 21].

Development of measurement methods, especially those for measuring energy quantities, has substantially extended possibility of research on sound radiation by structures as well as made it possible to calculate sound power radiated to a remote field on the basis of close-field measurements. Methods for quantitative and qualitative research on vibroacoustic energy propagation within space of complex boundary areas, have been developed. It has been connected with quantitative assessment of vibroacoustic energy stored in structural elements as well as assessment of energy radiated by the elements and also that transmitted in different ways $[2,7,14,20]$.

Contemporary structural dynamics in building engineering makes use of various research tools from the state identification area such as: boundary element method, finite element method and modal analysis methods, which enable - by modelling and investigating state changes - to better understand behaviour of complex structures, perform their optimization during design process and assess their current, often hazardous, states [4, 6, $12,20]$.

Acknowledging necessity of improving research methods dealing with quality of brick building structures for purposes of assessing their state, as well as safety factors for brick structures (see PN-B-03002 standard, p.3.1.3 and 4.6), in this work the author has undertaken an attempt to elaborate research methods for quality assessment of destruction of selected building structures by means of the operational modal analysis method [20, 21].

For this reason an important place is taken by nondestructive tests of brick wall elements in laboratory conditions, presently often used, as well as in-situ tests - by using sclerometric methods (indentation measurement method, rebound measurement method), impulse methods (ultrasonic and hammer ones), radiologic methods (radiographic, radiometric ones), electromagnetic methods (magnetic and dielectric ones) as well as special methods (e.g. electric ones) $[1,3,5,15,20]$.

It is necessary to improve methods for research on dynamic characteristics of structures especially those exposed on large dynamic loads. New materials and technology methods have been introduced to building engineering as well as novel structural solutions make it possible to increase productivity and quality of products, however they are accompanied with large, 
often dangerous dynamic loads. To the problems more and more attention has been presently devoted $[11,15,16,17,20]$.

In building engineeering, vibrations - a process which accompanies any motion - may be considered in the categories of noxiuos, favourable or information containing vibrations. Vibrations are primary process and their (secondary) effect is acoustic signal in the form of longitudinal sound wave. Vibration and noise processes form the basis for a scientific research area vibroacoustics. Modern building structures are accompanied by vibroacoustic phenomena which endanger people, environment, and their products. Trends of contemporary engineering and technology connected with rising dynamic loads, rotational speeds, minimization of weights and gabarites, make growing level of vibrations and noise inevitable. The tendencies together with mass application of technical means provide hazards to people, natural and technical environment $[2,7,10,13]$.

In most cases met in practice, analyses of dynamic properties are performed on the basis of analysis of structural model behaviour. Quality of the analysis depends on credibility of the model, which is measured by means of conformation of the object's behaviour and the model, both subject to disturbances of the same kind. Structural model may be built in the process of analytical transformations used for description of system's dynamics or on the basis of results of experiments performed on a real object $[3,8,9,20]$.

Analysis of dynamic properties of structure is carried out mainly by examining behaviour of dynamic model of a given structure, which is realized by using analytical description of quantities which characterize system's dynamics, or experimental methods directly applied to real objects $[13,21]$.

Novel tools in this research area deal with possible application of modal analysis methods as well as a modern ways of achieving and processing vibration process for assessing quality of brick wall structures and elements which is the subject of considerations in this work. In practical applications they make it possible to better understand behaviour of complex structures, optimize them during design process and assess hazardous states. In the latter area is contained the clue of the investigated problems, i.e. searching for assessment measures for degradation state of brick wall structures and elements, new and aged ones, and often those of unknown destruction state and safety factor values.

Modal analysis is widely used for investigating degradation state and fault location, modification of dynamics of tested structures, description and updating analytical model, as well as monitoring structural vibrations in aircraft and civil engineering. In the subject-matter literature the following notions can be found: modal analysis, experimental modal analysis and operational modal analysis $[4,8,9,13,20]$. In the majority of practical applications of modal analysis a multichannel experiment and complex calculations connected with the processing of measured signals and estimation of model's parameters, are required. The so seen application possibilities allows to distiguish the following kinds of modal analysis $[13,21]$ :

- theoretical - which requires to solve eigenvalue problem for a given structural model of investigated object,

- experimental - which requires to control identification experiment during which object's motion (e.g. vibration) is excited and measurements of excitation and response are performed in many measuring points,

- operational - which is based on experiment carried out in real conditions, during which only system's response is measured and object's motion results from real operational excitations.
From the beginning of 1990 close attention was more and more paid to possible application of the so called operational modal analysis (OMA) to testing the existing building structures. In this case object's vibrations (of platforms, buildings, towers and bridges) are excited by environment and only system's responses to generated vibrations, differentiated according to a degradation state, are measured.

In this paper are presented research results of differentiated state of building structure, obtained by applying the operational modal analysis. For this aim was used the LMS SCADAS Recorder, the device which combines features of analyzer and classical recorder, as well as LMS Test.Lab software serving for performing the tests and vizualizing their results [19].

\section{VIBRATIONS IN DESCRIPTION OF STRUCTURES}

Vibroacoustics is a domain of science which deals with any vibration, acoustic and pulsation processes occurring in nature, building engineering, technology, machines, devices, communication and transport means, i.e. in the environment. Among the tasks of vibroacoustics the following may be rated $[16,18]$ :

the identification of vibroacoustic energy sources which consists in location particular sources within structure of object, machine or environment, determination of their characteristics and mutual relationship, determination of vibroacoustic power as well as character of vibration and sound generation;

- the elaboration of vibroacoustic energy propagation paths in real structures and environment (buildings, machines, objects etc), theory of energy transmission and transformation, passive and active control means for phenomena, methods for analyzing and testing phenomena at the border area between wave and discrete approach;

- the elaboration of control methods for vibroacoustic energy (emission, propagation) in building structures, machines and environment, and also elaboration of methods for steering the phenomena, that is associated with active methods which are presently under development worldwide;

- the use of vibroacoustic signals for purposes of technical state diagnostics as they constitute a good carrier of information on state of object's destruction as well as technological process under way (vibroacoustic diagnostics);

- the vibroacoustic synthesis of objects, performed to obtain optimum vibroacoustic activity (structural, kinematic, dynamic one), which covers synthesis of parameters used in active methods for vibration and noise mitigation, and structural, kinematic and dynamic synthesis of objects and machines;

- the active applications of vibroacoustic energy to realizing various technological processes, beginning from ultrasonic welding and cleaning, transport of materials and machine elements along technological lines, consolidation of moulding sands, shaking out and cleaning castings, ending at consolidation of soils and concretes.

Vibroacoustic process may be presented as:

generation of time-varying forces acting onto a structure and its environment;

propagation and transformation of energy in different environment structures;

- sound radiation through material elements of environment. 
In analysis of vibroacoustic processes the following is taken into account:

- time - space distribution of run of energy coming from a (primary), source;

- response of a system (structure, liquid) as well as energy transmission through propagating media;

- mutual relationship between sources.

The notion of measurement means a process of acquisition and transformation of information about a measured quantity to get - by comparing it with measurement unit - a quantitative result in a form most comfortable to be acquired by human sense organs, its transmission in space or time (recording), mathematical processing or application to steering. To carry out such measurements is necessary for $[2,20]$ :

- the determining of time runs of vibrations and their parameters to determine kinds of the vibrations, their characteristic quantities and to perform detail analysis;

- the finding of vibration sources and places of their occurrence;

- the determining of characteristic features of systems (e.g. determining loads during vibrations and their dependence on object's parameters, its shape, dimensions, material properties etc);

- the minimizing of vibrations harmful for reliable operation of devices and their human operators;

- the determining of harmfulness level of occurring vibrations and the implementing of preventive measures.

In practice, vibration signal is more often used than noise one, due to its easiness of transferring and exactness of measuring $[5,16]$.

System's vibrations resulting from upsetting state of equilibrium of an object which then moves under action of elastic, gravity or friction forces, are called free vibrations. In one-degree-of-freedom (d.o.f) systems the upsetting of state of equilibrium is characterized by the initial conditions: the initial position $\mathrm{x}_{0}$ and initial velocity $\mathrm{v}_{\mathrm{o}}$. If the system is of one d.o.f. (single mass $\mathrm{m}$ ) and linear characteristics of elasticity (k) and damping (c) - Fig. 1, and the harmonic excitation force $\mathrm{F}(\mathrm{t})$ acts onto it, then its motion equation is expressed by the following formula:

$$
\mathrm{m} \stackrel{* *}{\mathrm{x}}+\mathrm{c} \stackrel{*}{\mathrm{x}}+\mathrm{kx}=\mathrm{F}(\mathrm{t})
$$

which represents the equation of harmonic vibrations or harmonic oscillator vibrations.

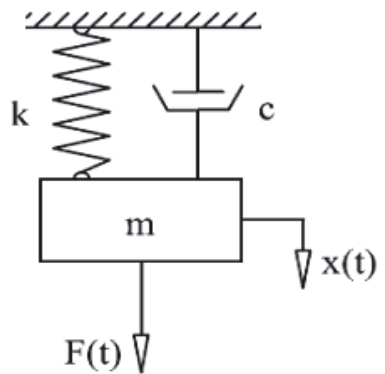

Fig. 1. One-d.o.f. system to perform translation motion

As results from it, natural vibration of one-d.o.f system is entirely determined by natural frequency of vibration. Amplitude of the vibration depends on initial conditions but natural frequencies and vibration period do not depend on them. The solution of the equation (i.e. translation) takes the following form:

$$
x=A \sin \left(\omega_{0} t+\varphi\right)
$$

By differentiating this equation the vibration velocity is obtained:

$$
\stackrel{*}{\mathrm{x}}=\mathrm{A} \omega_{0} \cos \left(\omega_{0} \mathrm{t}+\varphi\right)
$$

which is also a periodical function of time, of the same period as that of translation. And, by differentiating the velocity equation the value of vibration acceleration is obtained:

$$
\mathrm{x}=-\mathrm{A} \omega_{0}^{2} \sin \left(\omega_{0} \mathrm{t}+\varphi\right)=-\omega_{0}^{2} \mathrm{x}
$$

It is a periodical function of time, of the same period as that of translation and velocity. Acceleration is proportional to translation and directed against it, i.e. it always is pointing position of equilibrium.

The parameters: $\mathrm{a}, \mathrm{v}, \mathrm{x}-$ are those of vibration process, which convinces that the vibrations properly describe state of structure.

In the low frequency range, building structures can be modelled by means of discrete systems of a few d.o.f.s - and rather often - one - d.o.f system. The discrete system - in contrast to continuous one - is characterized by point distribution of mass, stiffness and damping and dimensions of the elements do not play any role. Number of d.o.f.s determines number of independent coordinates which should be introduced to get unambiguous description of system's motion (number of d.o.f.s is equal to number of mass elements in the system in question). In practice, the system presented in Fig. 1 can model:

- the building machine of mass $\mathbf{m}$, seated on shock absorbers $(\mathbf{k}, \mathbf{c})$ and fastened to a big mass fundation;

- the work machine of mass $\mathbf{m}$, seated on shock absorbers $(\mathbf{k}, \mathbf{c})$ and moving along an even road;

- the high building structure (high chimney, mast) under wind action.

Many systems can be preliminarily modelled by using one - d.o.f. system, to search for its properties by means of mathematical description and analysis of solutions of equations which describe it. It is possible to investigate system's properties by using the vibration parameters $(\stackrel{* *}{\mathrm{x}}, \stackrel{*}{\mathrm{x}}, \mathrm{x})$ which - being results of solutions of mathematical description of the model - interchangeably describe the same properties but from the viepoint of the system's vibration measuring process. In industrial practice it is common to measure vibrations instead to perform complex theoretical considerations.

The use of vibrations for testing quality of building structures results from the following reasons:

- vibration processes reflect physical phenomena occurring in structures (displacements, stresses, fractures), on which degree of their destruction (serviceability) and correct operation depends, that results from character of spreading the vibration process;

- easiness of performing measurments of vibration processes in normal operational conditions of an object without necessity of exclusion it from service and performing special preparation, hence it makes it possible to assess its state of destruction without disassembling the structure;

- vibration processes are characterized by a high speed of information transmission per time unit, defined by Shanon formula:

$$
\mathrm{C}=\mathrm{F} \lg _{2}\left(1+\frac{\mathrm{N}_{\mathrm{S}}}{\mathrm{N}_{\mathrm{Z}}}\right)
$$

dependening on spectrum band of the process $\mathrm{F}$ and the rate of the useful signal power $\mathrm{N}_{\mathrm{S}}$ and the disturbing noise power $\mathrm{N}_{\mathrm{Z}}$; 
- vibration processes are characterized by a complex structure of time, amplitude and frequency, which, if only correctly processed, makes it possible to assess state of entire structure as well as its particular elements.

During service of structure, due to occurrence of many external factors (excitations from the side of environment and other structures) and internal factors (ageing, wear, interaction of elements) in the structure take place disturbances of its equilibrium state, which propagate within elastic body, i.e. material of which the structure is made. The disturbances are of dynamic character and maintain equilibrium conditions between inertia, elasticity, damping and excitation state. Consequently, it results in energy dissipation of waves, their deflection, reflection and mutual superimposing. Existence of sources and propagation of disturbances cause vibration of structural elements and surrounding environment to occur.

When separating - during dynamic state analysis - the input processes $\mathrm{X}$, object's structure A and output processes $\mathrm{S}$, one should remember about their random character - Fig. 2.

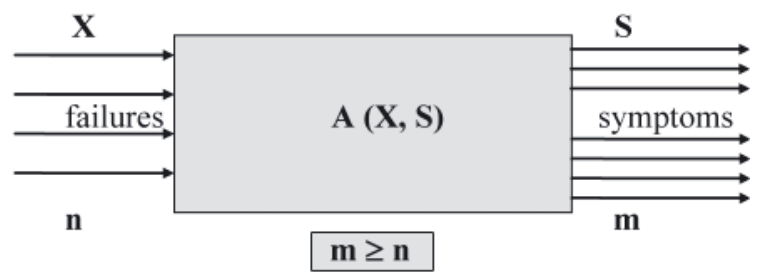

Fig. 2. Schematic model of an object and its description

Internal input taken as a set of excitation quantities which determine object's structure (shape, manufacturing quality, clearances etc) and a way of interaction of its elements is formed in random conditions during manufacturing, that reveals object's random properties in service.

External input which determine conditions of interaction between structure elements and other elements of a system (changes of loads, speed, environment impact) is also practically of a random character.

Many possible occurrences of randomness and disturbances result in additional assumptions dealing with inputs and occurring transformations of states of destruction of structures. They concern with assumptions on linearity, stationarity and ergodity of models of objects and processes [6, 12, 19, 20].

As a result of existence of the input and realization of transformation of states which represent processses occurring in structure, many measurable characteristic symptoms contained in output processes emitted from structure, are obtained. The processes form the basis for elaboration of a signal generation model which determines a way of forming, functioning and changing states of object's destruction [21].

\section{Features of model of transition of vibration signals for building structure in random disturbance conditions}

\section{The assumptions}

1. State of structure is unambigously determined by the characteristic signal $\varphi_{i}(t, \theta)$ generated seperately at every excitation. The signal undergoes changes within the dynamic (short) time $\mathrm{t}$ and evolution within the (long) time $\theta$.

2. The characteristic signal is composed of the determined process $\varphi_{\mathrm{o}}$ and random one $\mathrm{n}$ and its intensity and dynamics characterize state of destruction of structure. Hence, during i-th excitation the following signal is generated:

$$
\varphi_{\mathrm{i}}(\mathrm{t}, \theta)=\varphi_{0}(\mathrm{t}, \theta)+\mathrm{n}_{\mathrm{i}}(\mathrm{t}, \theta)
$$

3. The transformed characteristic signal which represents internal actions - material destruction - is achieved in the form of $y(t, \theta)$ and, in the simplest case, it constitutes response of a tested material of the characteristics $h(t, \theta)$ to the excitation $x(t, \theta)$. Taking into account the spatial wideness (dimensions) $r$ of structure one can write as follows:

$$
\mathrm{y}(\theta, \mathrm{r})=\sum_{\mathrm{i}=1}^{\infty} \varphi_{\mathrm{i}}(\mathrm{t}, \theta, \mathrm{r}) * \mathrm{~h}(\mathrm{t}, \theta, \mathrm{r}) * \delta(\mathrm{t}-\mathrm{iT})
$$

4. The output processes from structure reciprocately influence (selectively) destruction processes and consequently state of structure (element) due to positive destructive feedback, that deforms the initial signal $\varphi_{\mathrm{i}}(\mathrm{t}, \theta)$.

5. For a given value of service time, $\theta_{\mathrm{i}}=$ const, all building objects are considered to be linear, stationary systems whose features are unambiguously described by the impulse response $\mathrm{h}(\mathrm{t}, \theta, \mathrm{r})$ or its tramsforms: Laplace operator, $\mathrm{H}(\mathrm{p}, \theta, \mathrm{r})$, or Fourier spectrum, $\mathrm{H}(\mathrm{j} \omega, \theta, \mathrm{r})$.

The above described set of assumptions which leads to a model of generation of signals can be presented in the form of the schematic diagram shown in Fig. 3.

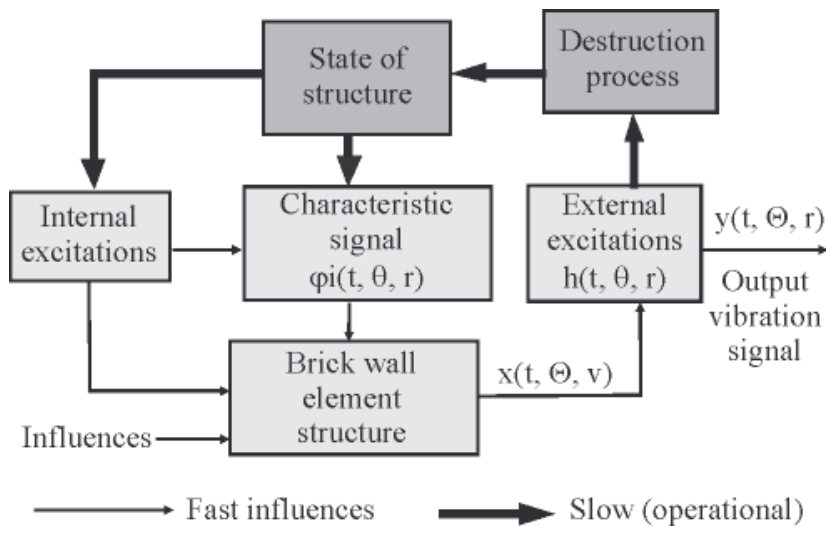

Fig. 3. Model of signal transmission through tested brick wall element

The output vibration signal at any reception point can be approximately expressed by the following formula $[2,16]$

$$
\mathrm{y}_{\mathrm{k}}(\theta, \mathrm{r})=\sum_{\mathrm{i}=1}^{\mathrm{k}} \mathrm{a}(\mathrm{k}) \mathrm{h}_{\mathrm{i}}(\mathrm{t}, \theta, \mathrm{r}) *\left[\mathrm{u}_{\mathrm{i}}(\mathrm{t}, \theta, \mathrm{r})+\mathrm{n}_{\mathrm{i}}(\mathrm{t}, \theta, \mathrm{r})\right]
$$

where:

- the impulse transition function $\mathbf{h}\left({ }^{*}\right)$ which covers material destruction properties;

- $\mathbf{a}(\mathbf{k})$ - term which provides different summation weights connected with the reception place $r$.

The above presented way of interpretation of the output signal $(\theta, r)$ is - in the general case of excitations of periodical service objects - correct, but not always so simple as that shown in Fig. 4 where is illustrated occurrence of excitations due to random actions of wind onto high buildings, chimneys, towers, and record of relevant response in the form of complex vibration signal.

The output signal received in an arbitrary point of structure is the weighted sum of responses to all elementary events $\varphi \mathrm{i}(\mathrm{t}, \theta, \mathrm{r})$ which occur always in the same sequence in particular points of the dynamic system of the pulse transition function $\mathrm{h}(\mathrm{t}, \theta, \mathrm{r})$. 


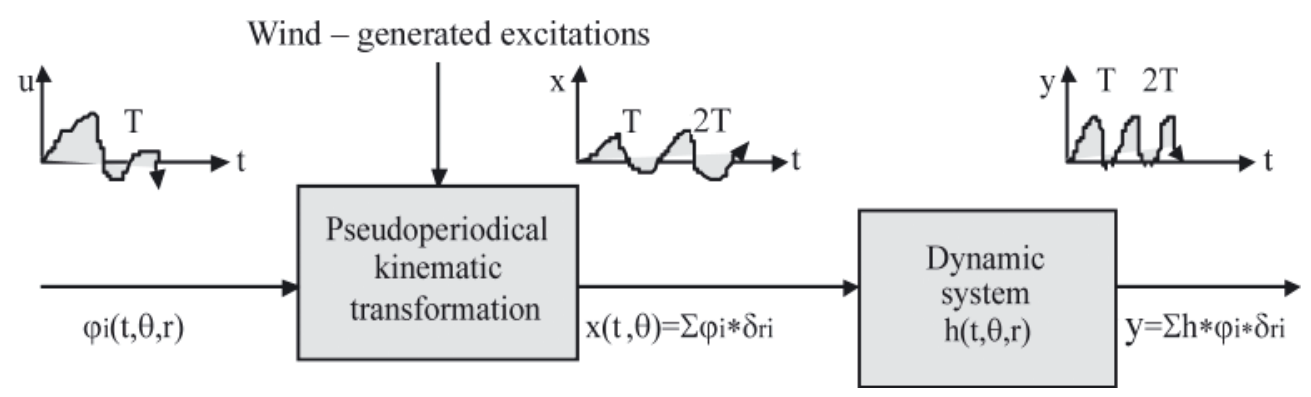

Fig. 4. Transformation of the characteristic signal $\left.\varphi i^{*} *\right)$ into the output signal $y(*)$,

considered to be a model of signal generation in objects under environmental excitation [7, 21$]$

The influences sum up together and subject to additional transformation along different reference axes, and a change of signal reception point $r$ is associated also with change of transmittance.

Model of vibration signal transmitting through tested structures or brick wall elements is described practically by FRF function which is determined by means of experimental modal analysis in the form of ratio of vibration excitation force and vibration acceleration amplitude at output. The transmittance $\mathrm{H}(\mathrm{f})$ defined as the response-to-excitation ratio is inversion of the FRF function.

The indicated properties of the elaborated model of signal transition through tested materials were further used for assessing changes of degree of degradation of structures or brick wall elements during testing transition of vibration signals through various structures of brick wall elements and segments.

Modal analysis is widely applied to removing damages resulting from vibrations, modifying structure dynamics, updating analytical model or state control, and also used for monitoring vibrations in aircraft industry and civil engineering $[7,9,13,19]$.

Theoretical modal analysis is defined as a matrix eigenvalue problem dependent on matrices of mass, stiffness and damping. It requires the eigenvalue problem for an assumed structural model of investigated structure to be solved [13, 21]. The determined sets of natural frequencies, damping coefficients for the natural frequencies and forms of natural vibrations make it possible to simulate behaviour of structure under arbitrary excitations, choice of steering means, structural modifications and other issues.

Analysis of natural fequencies and vectors is obtained on the basis of motion equations (after neglecting terms which contain damping matrix and external load vector). Then the motion equation of natural vibrations obtains the following form:

$$
\mathrm{B} \ddot{\mathrm{q}}+\mathrm{Kq}=0
$$

For one d.o.f. system its solution is as follows:

$$
\mathrm{q}(\mathrm{t})=\overrightarrow{\mathrm{q}} \sin (\varpi \mathrm{t}+\varphi)
$$

where:

$\overrightarrow{\mathrm{q}}$ - vector of amplitudes of natural vibrations.

On substitution of the above given equation and $2^{\text {nd }}$ derivative to the motion equation the following is obtained:

$$
\left(-\varpi^{2} \mathrm{~B}+\mathrm{K}\right) \overrightarrow{\mathrm{q}} \sin (\varpi \mathrm{t}+\varphi)=0
$$

The equation is to be satisfied for arbitrary instant $t$, then the set of algebraic equations is yielded as follows:

$$
\begin{gathered}
\left(K-\varpi^{2} B\right) \vec{q}=0 \\
\left(k_{11}-\omega^{2} m_{11}\right) q_{1}+\left(k_{12}-\omega^{2} m_{12}\right) q_{2}+ \\
+\cdots+\left(k_{1 n}-\omega^{2} m_{1 n}\right) q_{n}=0 \\
\left(k_{21}-\omega^{2} m_{21}\right) q_{1}+\left(k_{22}-\omega^{2} m_{22}\right) q_{2}+ \\
+\cdots+\left(k_{2 n}-\omega^{2} m_{2 n}\right) q_{n}=0 \\
\cdots \cdots \cdots \cdots \cdots \cdots \cdots \cdots \cdots \\
\left(k_{41}-\omega^{2} m_{41}\right) q_{1}+\left(k_{42}-\omega^{2} m_{42}\right) q_{2}+ \\
+\cdots+\left(k_{n n}-\omega^{2} m_{n n}\right) q_{n}=0
\end{gathered}
$$

This way was produced the set of linear homogeneous algebraic equations, which has non-zero solution only when the condition:

$$
\operatorname{det}\left(K-\varpi^{2} B\right)=0
$$

is fulfilled.

On transformations the n-order polynomial is obtained. Among its roots multifold ones may be present, and the vector built from the set of frequencies $\varpi^{2}$ ordered according to increasing value sequence is called the frequency vector, and the first frequency is called the fundamental one [21].

$$
\varpi=\left[\varpi_{1}, \varpi_{2} \ldots ., \varpi_{\mathrm{n}}\right]
$$

The theoretical modal analysis is mainly used in design process, i.e.when it is not possible to perform tests on objects.

The traditional experimental modal analysis (EAM) makes use of input (excitation) to output (response) relation and it is measured in order to assess modal parameters consisted of modal frequencies and damping. However the traditional EAM has some limitations such as:

- in the traditional EAM, artificial excitation is used to measure vibration frequencies,

- the traditional EAM is usually performed in laboratory conditions.

However in many cases a real state of degradation may greatly differ from those observed in laboratory environment. In experimental modal analysis the identification experiment consists in exciting object's vibrations at simultaneous measuring excitation force and system's response usually in the form of vibration acceleration amplitude.

Beginning from 1990 more and more attention has been paid to application of the operational (service) modal analysis (OMA) to the testing of existing building structures. In this case the environment serves as a vibration exciter 
for platforms, buildings, towers, bridges etc. Only system's responses to vibrations generated by the environment are measured, Fig. 5.

Accelerometers are shitted successively into points of signal reception

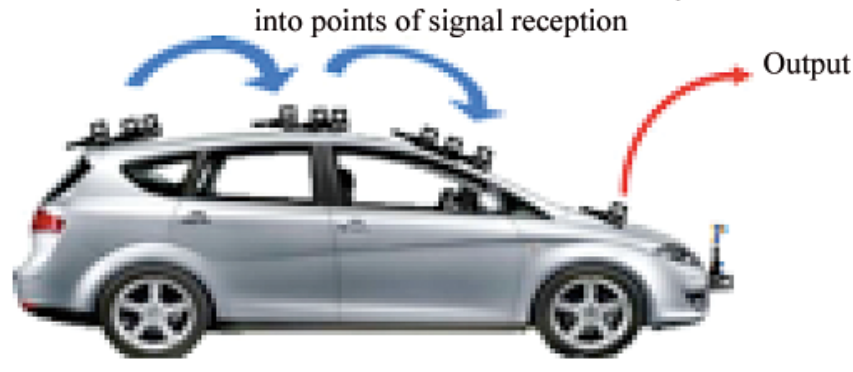

Operational excitations

Fig. 5. Essence of the operational modal analysis

The OMA is very attractive for industrial testing due to its many merits such as:

- it is cheap and allows to fast carry out measurements; - lack of the problem with artificial excitation of vibrations; assessing dynamic features of entire existing system is possible;

operation of the simple measuring instruments is easy;

- testing results which are more representative than those from laboratory, can be obtained;

- because of a broad band of random excitation testing results are more representative.

As a result of modal analysis, is obtained a modal model of structure, which can be used for solving many engineering problems, e.g. synthesis of building systems, analysis of structure behaviour under action of various excitations, modification of dynamic properties, minimization of acoustic energy radiation, fatigue analysis.

The modal model of tested building structure (or its elements) is considered as an ordered set of natural frequencies, damping coefficients as well as vibration forms for particular loading excitations $[6,13,20]$.

By making use of the statement that state of destruction of object (tested material) can be alternatively described, instead to model changes in the categories $(\mathbf{m}, \mathbf{k}, \mathbf{c})$, by the vibration

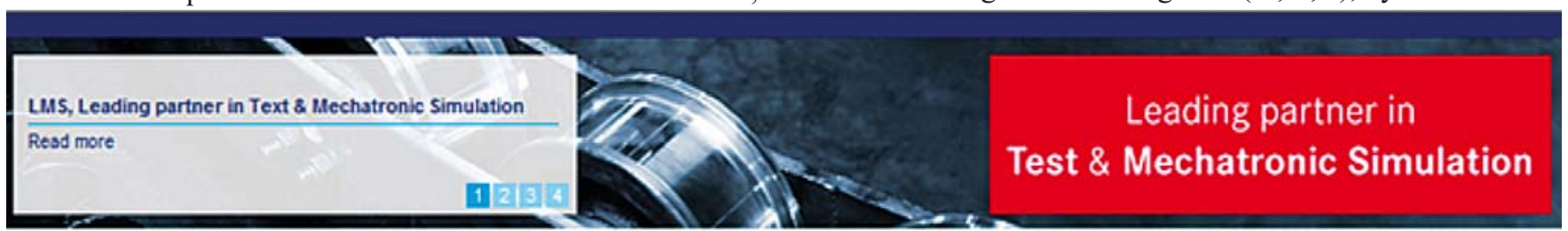

* Engineering Innovation WWS, the leading partner in test and mechatronic simulation in the automotive, aero. space and other advanced manufacturing industries, helps customers get better products to rarket faster. Wh a unibue combination of mechatronic simulation software, testing systems and engineering services, LUS tunes into mission crtical engineering attroutes, ranging from system Gynamics, structural integrty and sound qualty to durability, safety and powee consump-tion. What muti-domain and mechatronic simulation solvions, LUS addresses complex engineering challenges associated wh intelloent system design and modelbased systems engheering More than 900 LUS professionals serve over 5,000 manufacturing companies worlowide. $\rightarrow$ IAEHR

\section{" Ressourcen}
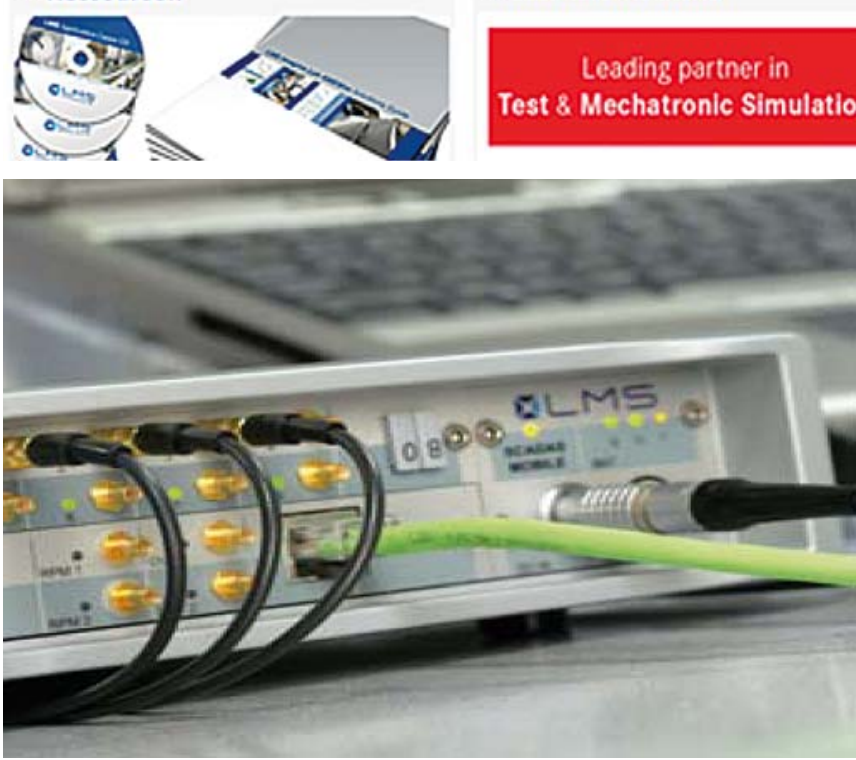

Fig. 6. The web site and LMS instrument

Strukturuntersuchung | Schwingprüfung |
* LMS International
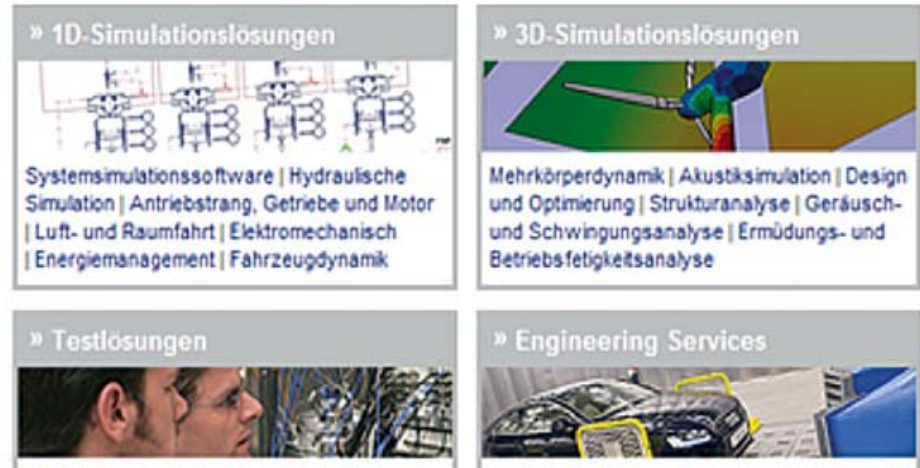
Gerausch- und Schwingungsanalysstor ] Untersuchungen rotierender Komponenten | 1Lessdatenerfossungsgerát | Alustiktest

Leading partner in Test \& Mechatronic Simulation

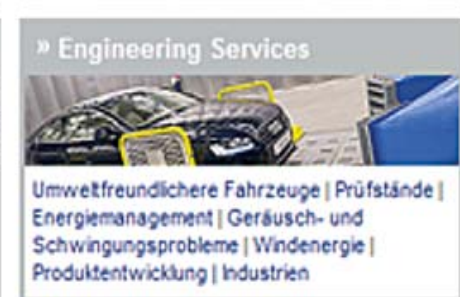

" LMS News magazine issue 25

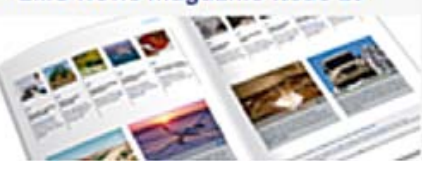

» L.MS Veranstaltungen

$\$$ Seminare

Gerausch und Schwhoungsmiderungen

Grundagen der

Betriebs festigket -

Konzepto und Methoden

tür die Praxis

$\$$ Web-Seminare

$\checkmark$ Messen und Kongresse

$\checkmark$ Schulungen

\LMS Konferenz $\rightarrow$ HEHR

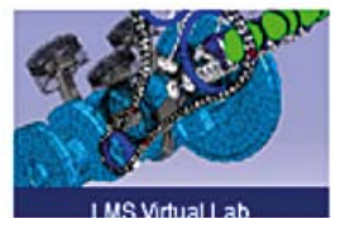

description in the categories $(\mathbf{a}, \mathbf{v}, \mathbf{x})]$ - as is the case in the tests in question, one could assess state of degradation of structures or brick wall elements by means of natural vibration frequencies directly resulting from modal analysis.

Determining individual modal models for partial excitations in a tested element and further summing up them for the entire object's structure, one obtains an evolutionary model which unambiguously describes changes in state estimators in varying load conditions. This way is revealed fractal nature of energy transformation processes, which makes possible ways of approximating description of real world, more perfect.

\section{MEASUREMENT SOFTWARE}

The recorded vibration signals (excitations and responses) are subject to rather complicated processing for purposes of 
determination of measures of destruction state of brick wall elements and structures [13, 21].

For measuring time runs of system's excitation and response as well as determining modal model parameters during the testing the LMS TEST.XPRESS instrument, the most modern measuring device, was used (Fig. 6). The device and relevant software makes it possible to easily perform modal analysis of brick elements as well as another building structures.

The software in question is equipped with a user-friendly interface. After starting the software one should open a new project and call it according to its task. Beginning from this moment all the performed measurements will be recorded in this active project - Fig. 7 .
The first step is to define a system in the aspect of calibration of measurement channel. For purposes of the tests performed during the present stage the action was started from the defining of a number of active measurement channels. Their number is limited only by a number of inputs on the measurement card, which is different for different models of measurement segments.

The dialogue window open during measurements is presented in Fig. 8.

The LMS software makes it possible to produce a stabilization diagram for a given single measurement (option: „Selected function") as well as to produce a stabilization diagram from all measurements together (option: „SUM”). The example

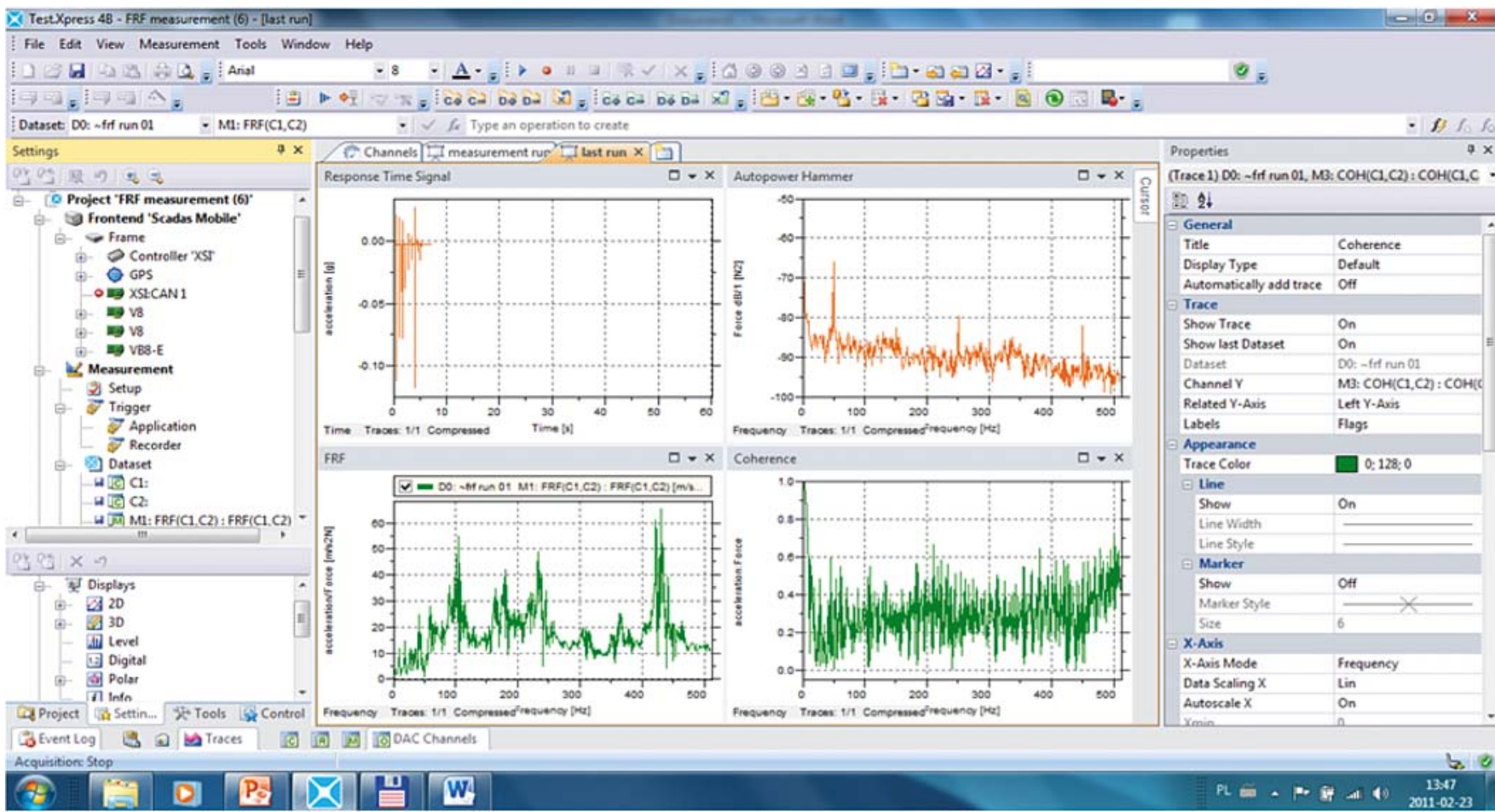

Fig. 7. Interface of LMS software

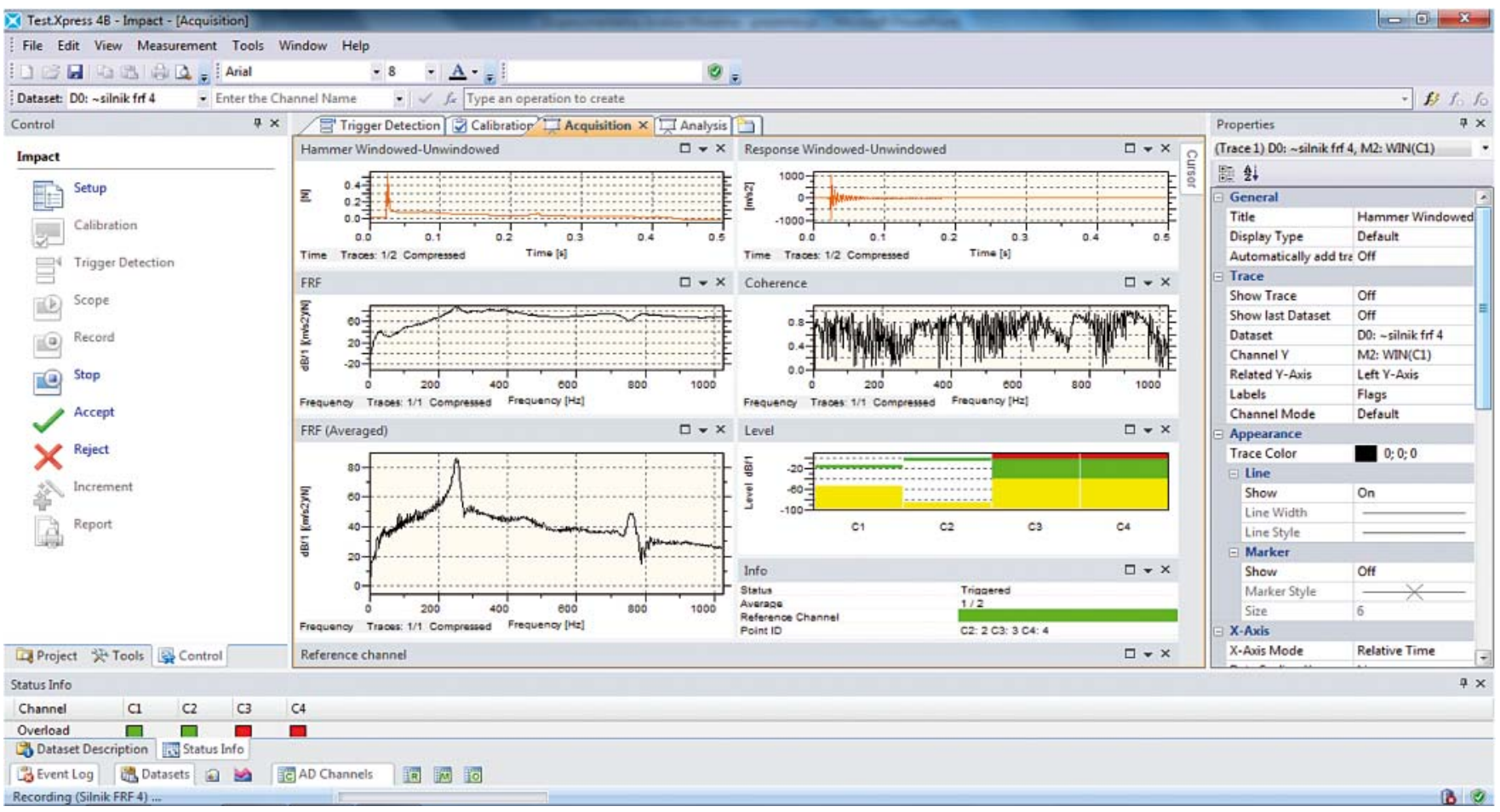

Fig. 8. The main dialogue window during measurements 


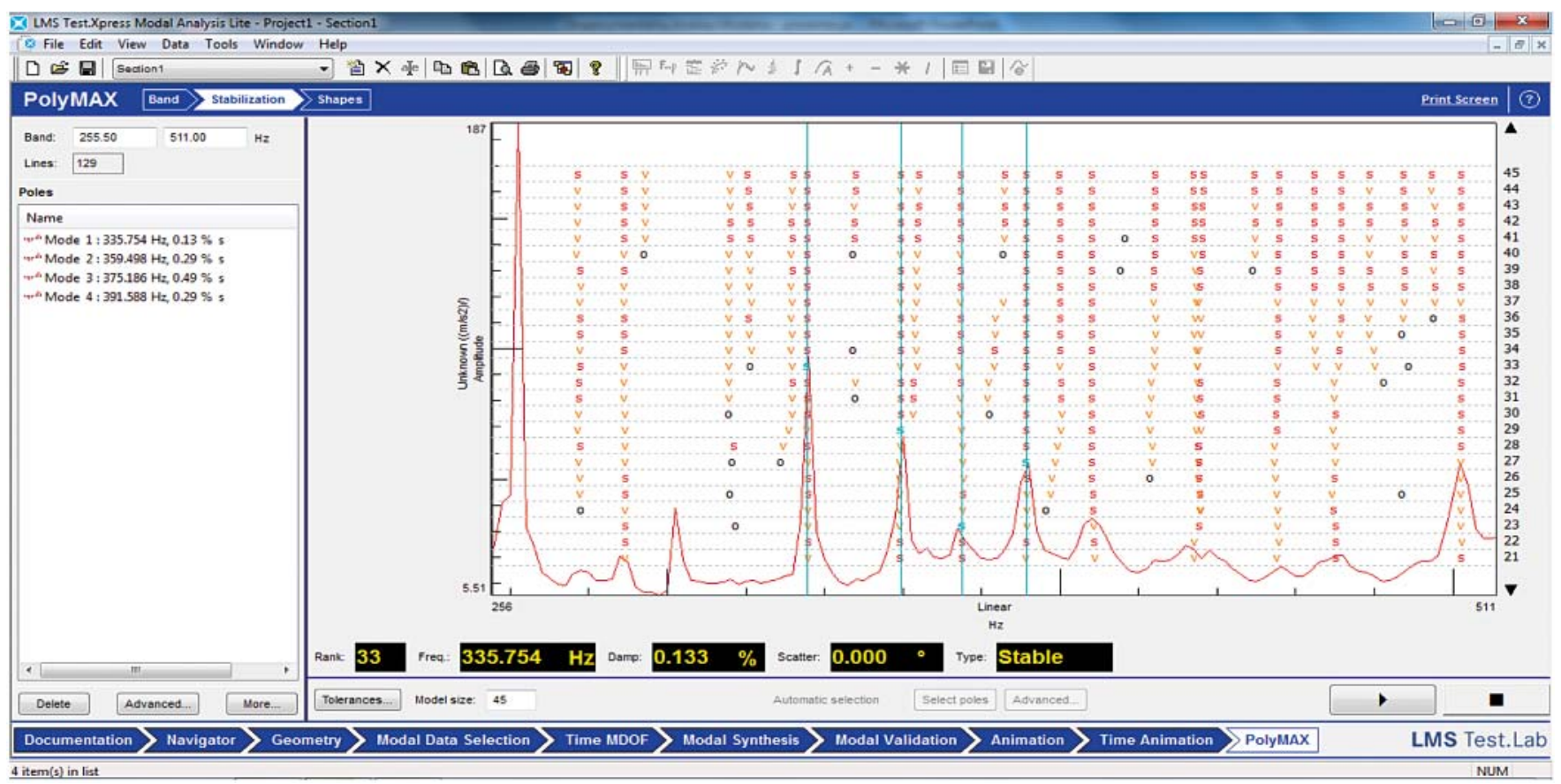

Fig. 9. „, Stabilization” window displaying a stabilization diagram

stabilization diagram is shown in Fig. 9. where poles are marked as follows: $\mathrm{S}$ - stable, $\mathrm{V}$ - modal vector, $\mathrm{D}$ - damping. The option „Mode" available in the software is capable of visualizing deformations of geometrical model.

In Fig. 10 is shown testing instrumentation (modal hammer, LMS SCADAS Recorder) and examples of materials selected for testing, and a view of tested building structure.
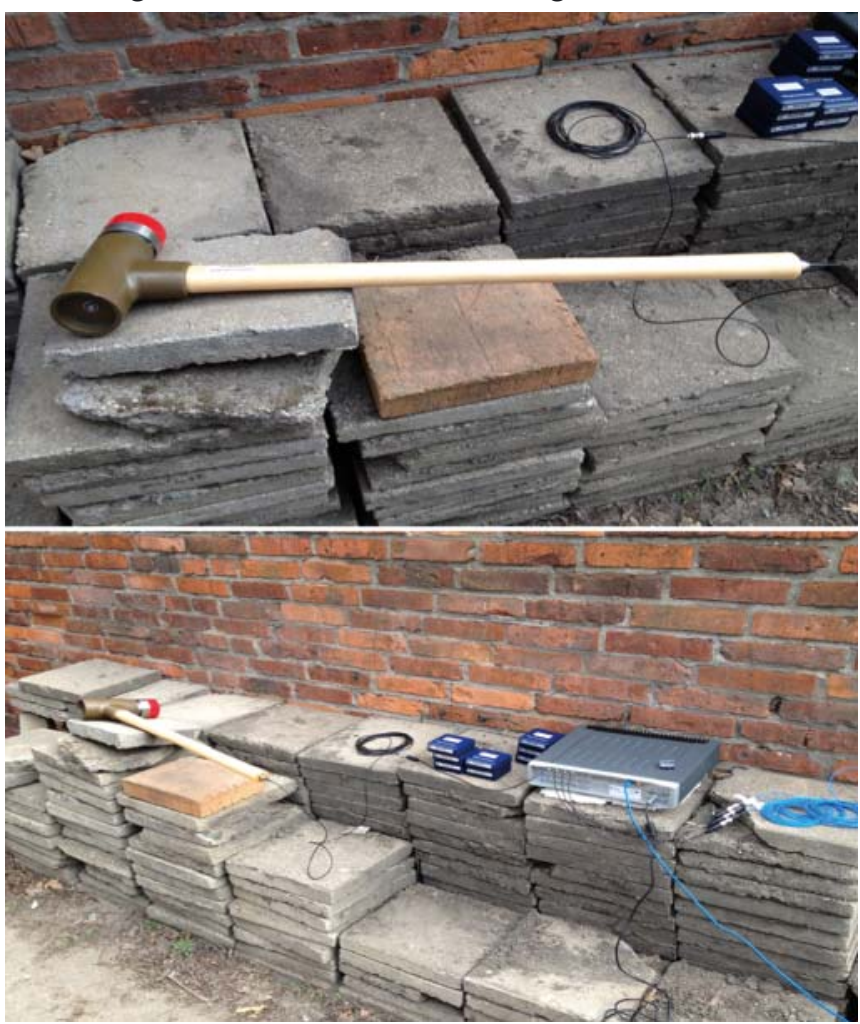

Fig. 10. View of materials, a fragment of structure used for testing, and testing instrumentation

The tests were performed for two existing building structures. The first of them was a brick wall of $18 \mathrm{~cm}$ in thickness and $200 \mathrm{~cm}$ in height. The wall structure was tested both in place of a damage which produced drop of strength and endangered safety of the structure, and - for comparison - the same wall structure but in place of its correct (serviceable) state. (Fig. 11).

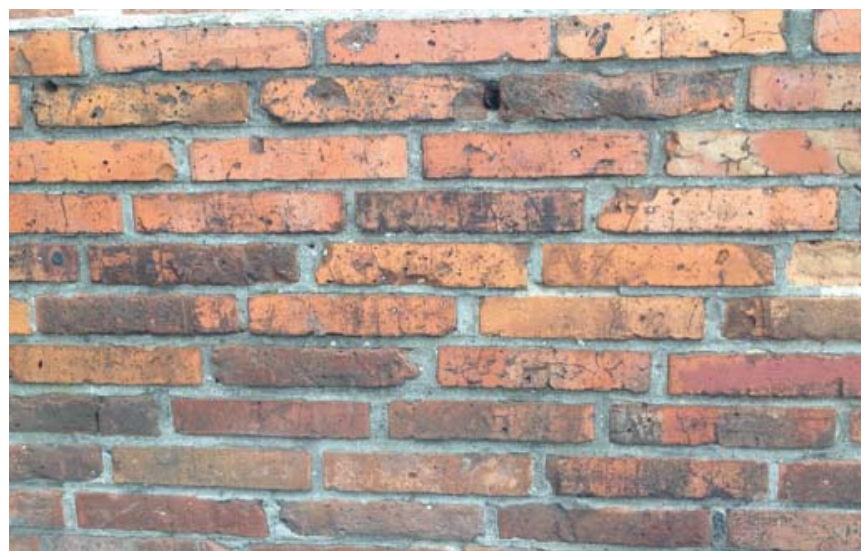

Fig. 11. View of both serviceable and damaged brick wall structure

In the first case gauges were placed on a surface without any symptoms of faults and then measurements were performed for the structure modelled as that serviceable. Next, the gauges were fixed between the existing fracture on the wall and for this arrangement of gauges the measurements were done.

Another existing building structure under testing was a reinforced concrete wall of a didactic building, deriberately structurally weakened by two cuts (scratches) made to change its stiffness. For purposes of testing by using operational modal analysis, 8 measuring channels were defined. In compliance with the theoretical assumptions of the modal analysis the first response gauge was defined to be reference one, and the next seven - the structural response gauges. Owing to that it was possible to determine the cross-correlation function for signal transition through tested structure, which is the basis for signal processing. Preparation of the object to the tests consisted of arranging and fastening the gauges for measurements, Fig. 12, their connection with the measuring device and calibration of the entire system. 


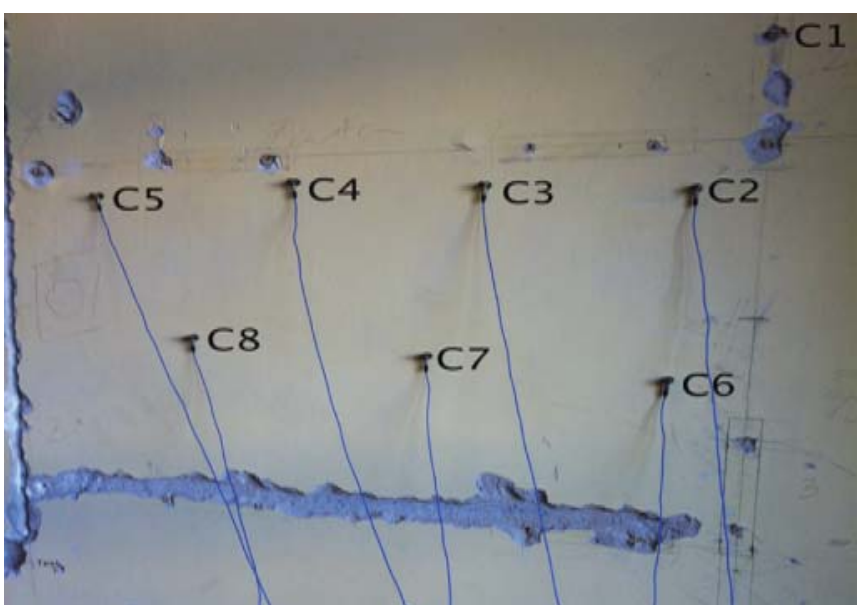

Fig. 12. View of the tested wall structure and arrangement of the gauges

\section{RESULTS OF THE TESTS}

Results of the tests are presented in the following sequence: first, for the wall shown in Fig. 13, where the cross- corelation functions were measured between the reference point (C1 gauge) whose place was selected according to the theory of operational modal analysis, and seven gauges assumed in the model and placed on the structure in question. On the basis of the generated cross-power spectrum function it was possible, in the further stage of signal processing, to generate stabilization diagrams and next fundamental vibration frequencies.

To visualize possible changes of structure degradation the measurements were performed in a few variants. It was at first the measurements made for serviceable and unserviceable structure without any external interference, and then the comparative tests carried out for serviceable and unserviceable structure at simultaneous excitation of vibrations by rhythmic knocking onto structure with the use of the modal hammer. Each test lasted 30 seconds.

Below, are presented selected results of the tests in the form of visualization of stabilization diagrams and deformations occurring in different dynamic states of the structure.

Near, is presented Tab. 1 which contains the set of the natural vibration frequencies generated for measuring different states of degradation of the existing brick structure.

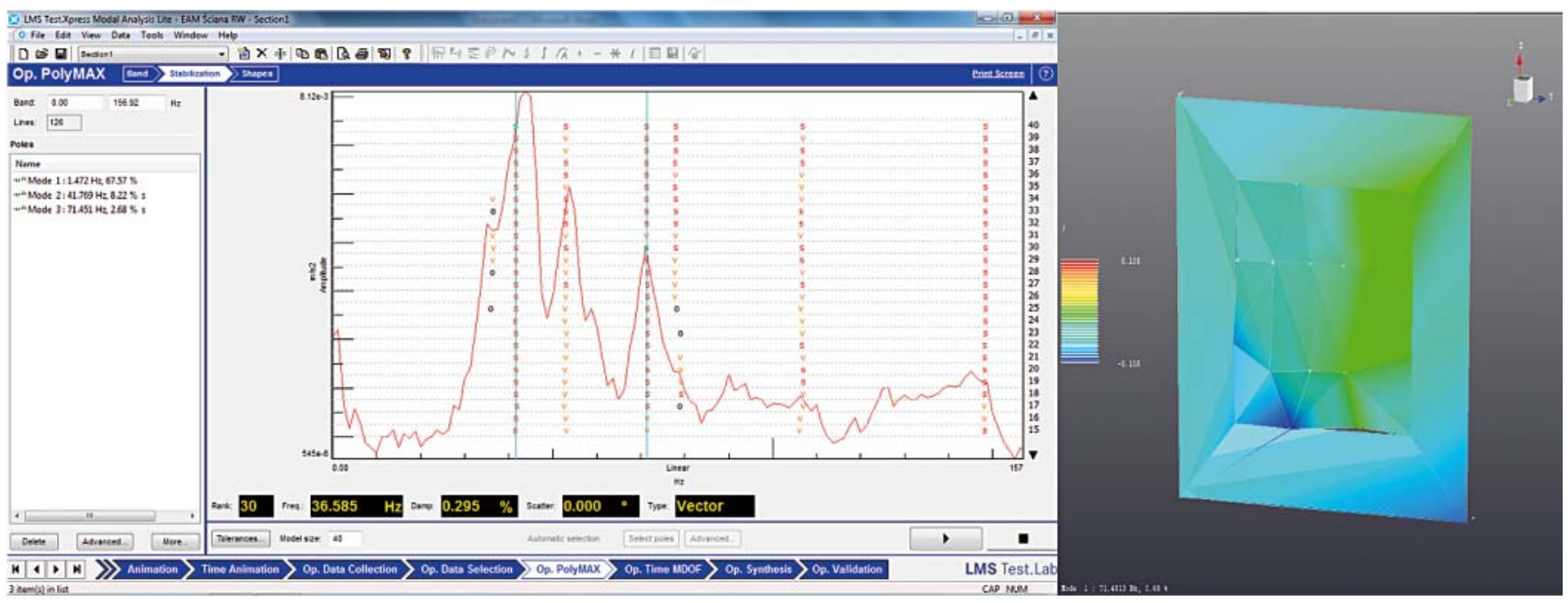

Fig. 13. Test results for the wall without damages, under excitations

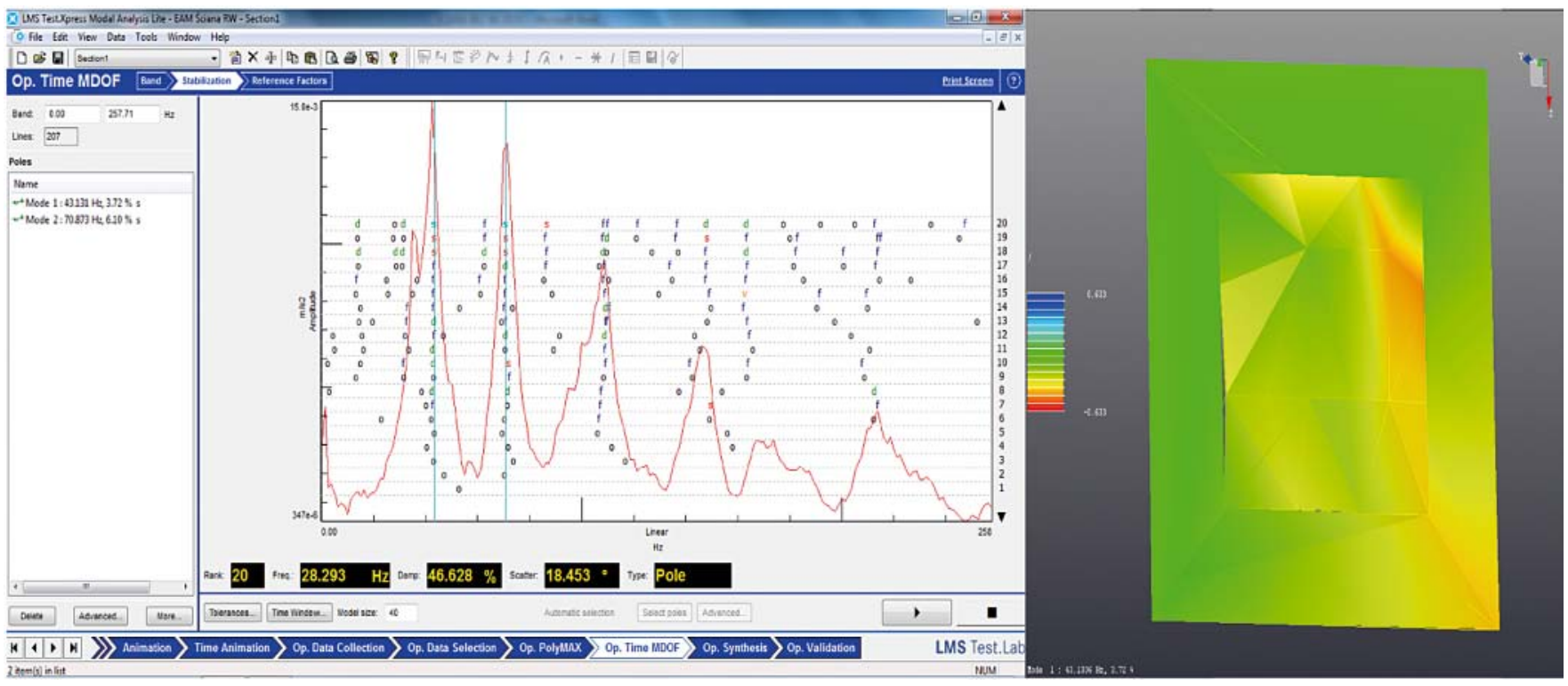

Fig. 14. Test results for the wall with one scratch, under excitations 


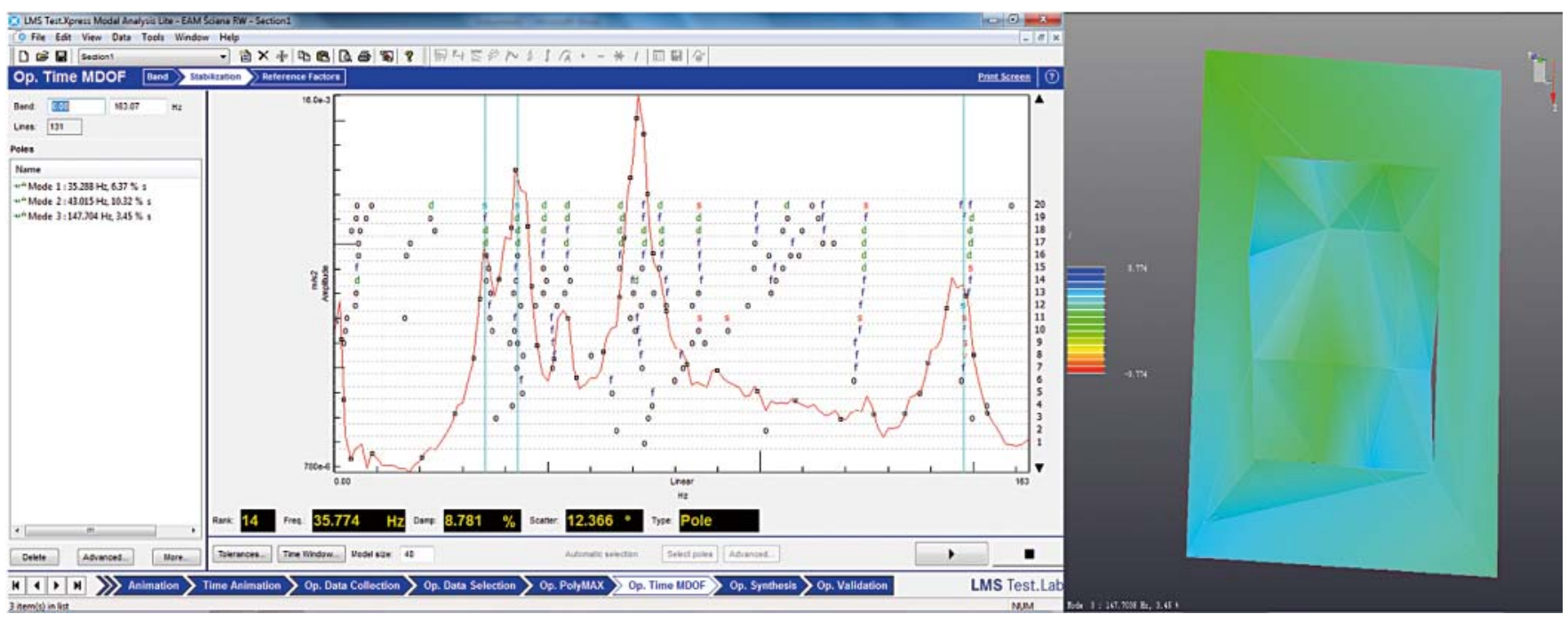

Fig. 15. Test results for the wall with two scratches, under excitations

Tab. 1. Set of natural vibration frequencies for different states of degradation of the brick structure

\begin{tabular}{|c|c|c|c|}
\hline EXCITATIONS & $\begin{array}{c}\text { Serviceable } \\
\text { wall }\end{array}$ & $\begin{array}{c}\text { Wall with } \\
\text { one scratch }\end{array}$ & $\begin{array}{c}\text { Wall with } \\
\text { two scratches }\end{array}$ \\
\hline without excitation & $71.388 \mathrm{~Hz}$ & $39.999 \mathrm{~Hz}$ & $29.831 \mathrm{~Hz}$ \\
\hline without excitation & $81.699 \mathrm{~Hz}$ & $40.806 \mathrm{~Hz}$ & $39.207 \mathrm{~Hz}$ \\
\hline with excitation & $43.526 \mathrm{~Hz}$ & $41.271 \mathrm{~Hz}$ & $70.844 \mathrm{~Hz}$ \\
\hline with excitation & $81.699 \mathrm{~Hz}$ & $147.588 \mathrm{~Hz}$ & $110.296 \mathrm{~Hz}$ \\
\hline
\end{tabular}

Quantitative results of testing the brick wall without damages as well as that with damages (see Fig. 13) performed with the use of the method of operational modal analysis are presented in successive figures. The complete set of natural vibration frequencies characteristic for the tested states of degradation of the wall, obtained with the use the experimental and operational modal analysis, is presented in Tab. 2.
Below, is presented Tab. 2 which contains the set of natural vibration frequencies generated during testing the existing brick wall.

Tab. 2. The complete set of natural vibration frequencies for the tested brick wall

\begin{tabular}{|c|c|c|}
\hline EXCITATIONS & $\begin{array}{c}\text { Serviceable } \\
\text { element }\end{array}$ & Damaged element \\
\hline & & $1025.813 \mathrm{~Hz}$ \\
with excitation & $865.612 \mathrm{~Hz}$ & $1060.857 \mathrm{~Hz}$ \\
(EAM) & & $1112.476 \mathrm{~Hz}$ \\
& & $2.607 \mathrm{~Hz}$ \\
\hline without excitation & $0.777 \mathrm{~Hz}$ & $4.446 \mathrm{~Hz}$ \\
(OAM) & & $15.417 \mathrm{~Hz}$ \\
\hline with excitation & $0.805 \mathrm{~Hz}$ & $0.772 \mathrm{~Hz}$ \\
(OAM) & & $14.043 \mathrm{~Hz}$ \\
\hline
\end{tabular}

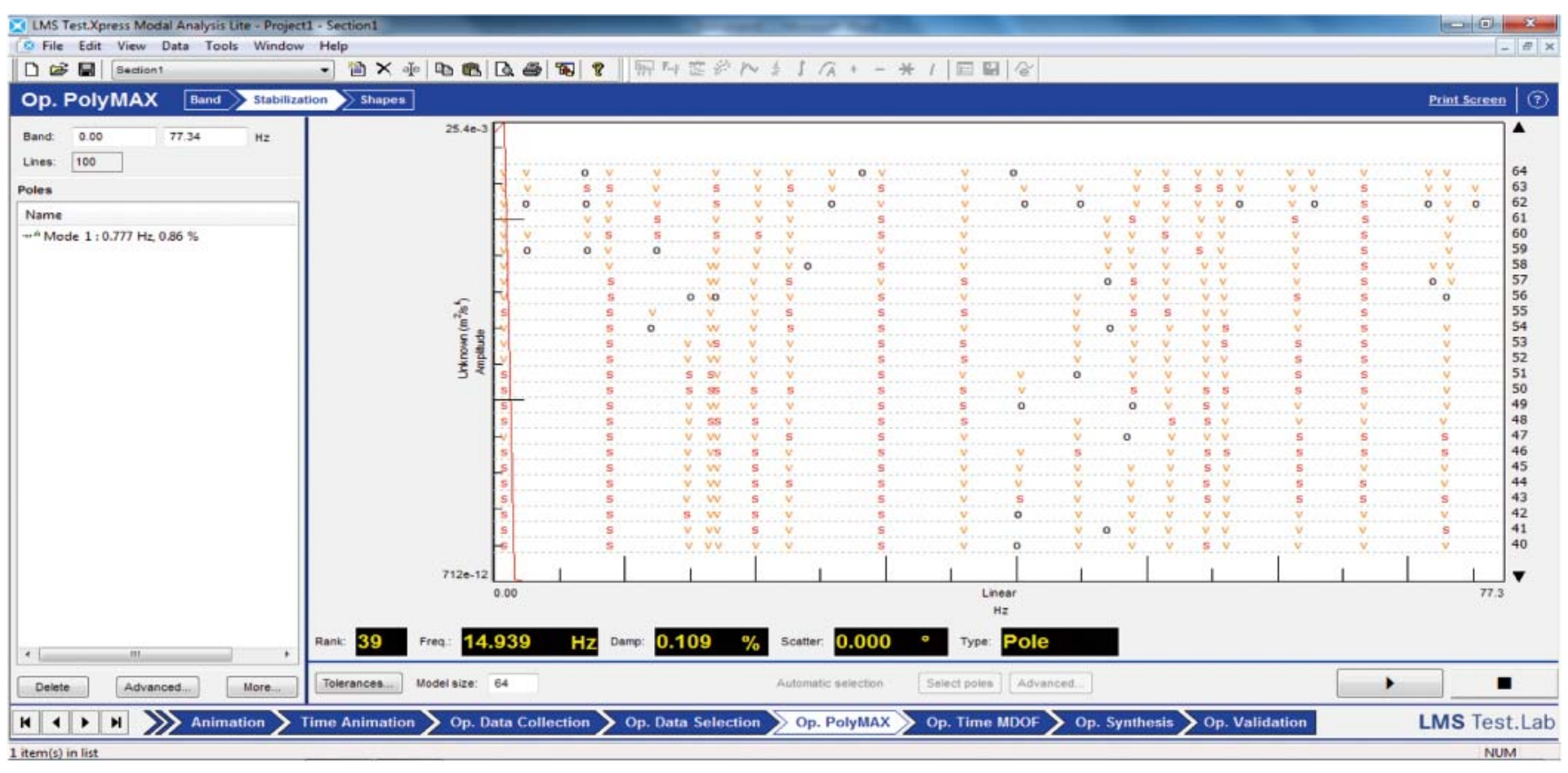

Fig. 16. Stabilization diagram for the serviceable brick wall (OAM) 


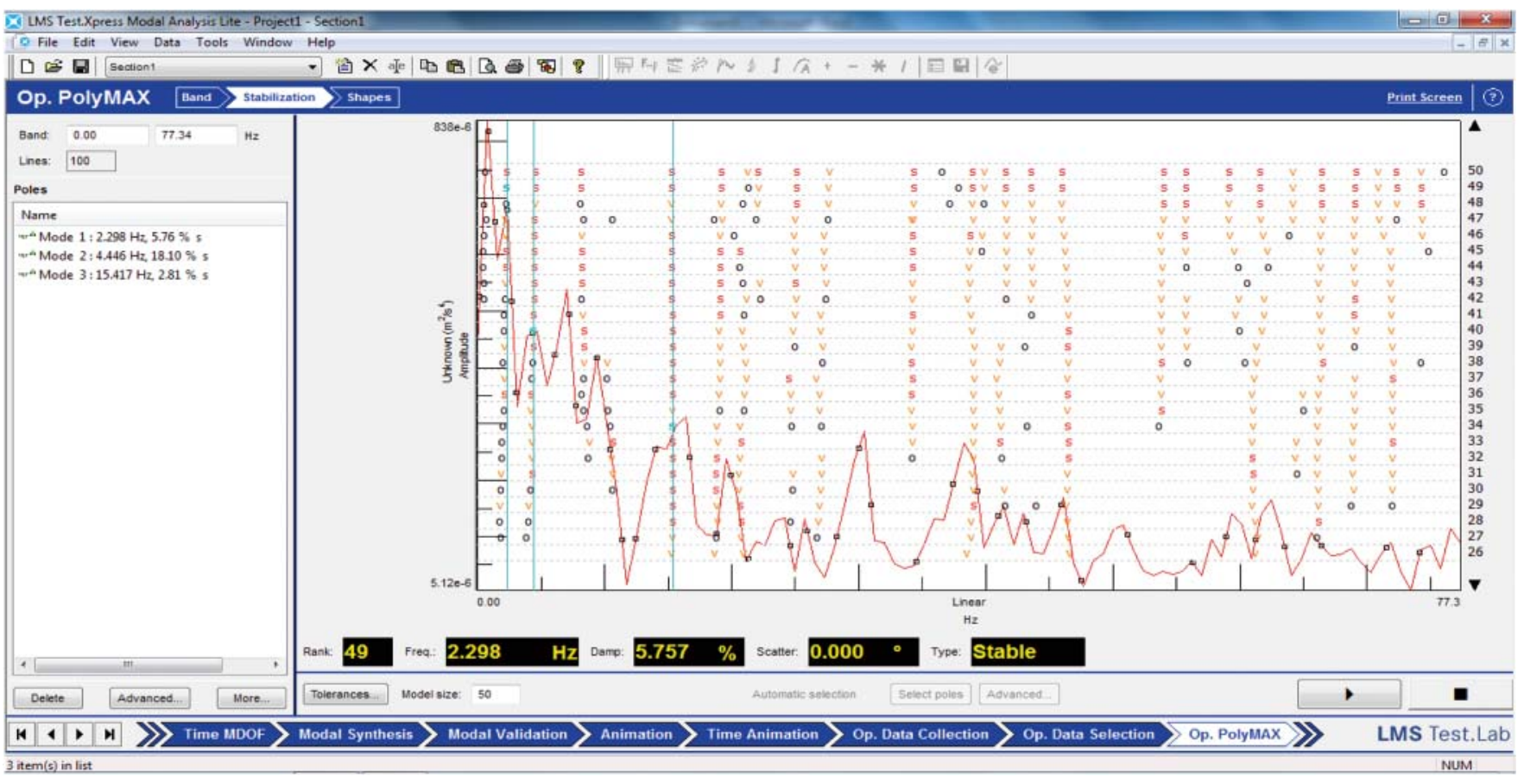

Fig. 17. Stabilization diagram for the damaged brick wall (OAM)

\section{CONCLUSIONS}

The searching for of non-destructive testing methods for buildings and harbour structures indicates that to apply modal analysis to assess their degradation is possible, that has been shown in this paper. Out of different available kinds of form of modal analysis the operational modal analysis was used to the reported investigations on structure destruction.

The presented results of the testing indicate that it is possible to distinguish degradation features of brick materials, that show influence on possible assessment of hazards and their strength aspects. The in-situ and operational tests confirmed that the LMS instruments are useful for performing operational modal analysis of real building structures.

From the presented test results it can be preliminarily concluded that for the serviceable brick wall structures the generated natural vibration frequencies were contained within the range of $70 \div 80 \mathrm{~Hz}$. For the damaged structures the generated natural vibration frequencies were of much lower values, i.e. in the range of $30 \div 40 \mathrm{~Hz}$. The implemented graphic presentation of deformations resulting from action of natural vibrations of a given frequency is useful for qualitative assessment of degradation state.

The practically verified sensitivity of assessment of modal analysis to degree of brick structure degradation, reveals - in a practically satisfactory degree - differences between serviceable structure and damaged one. Therefore it becomes possible to determine hazards to a building (harbour) structure on the basis of examining values of frequencies of natural vibrations and their forms by using the operational modal analysis.

\section{BIBLIOGRAPHY}

1. Batel M.: Operational modal analysis - another way of doing modal testing. Sound and Vibration, August 2002.

2. Bishop R., Johnson D.: The mechanics of vibration. Cambridge University, Press, 1980.

3. Brandt S.: Data analysis (in Polish). Wydawnictwo Naukowe PWN (Scientific Publishing House), Warszawa 1999.

4. Brown D., Allemang R.: Multiple Input Experimental Modal
Analysis. Fall Technical Meeting, Society of Experimental Stress Analysis, Salt Lake City, UT, November 1983.

5. Brunarski L.: Non-destructive methods for concrete testing (in Polish). Arkady, Warszawa 1996.

6. Formenti D., Richardson M.: Parameter estimation from frequency response measurements using rational fraction polynomials (twenty years of progress). Proceedings of International Modal Analysis Conference XX, Los Angeles, CA, February 4-7, 2002.

7. Ibrahim S., Mikulcik E.A.: Method for the direct identification of vibration parameters from the free response. Shock and Vibration Bulletin, Vol. 47, Part 4, 1977.

8. Peeters B., Ventura C.: Comparative study of modal analysis techniques for bridge dynamic characteristics. Submitted to Mechanical Systems and Signal Processing, 2001.

9. Pickrel C.R.: Airplane ground vibration testing - nominal modal model correlation. Sound and Vibration, November 2002.

10.Richardson M.: Is it a mode shape or an operating deflection shape? Sound and Vibration, February 1997.

11.Richardson M.: Structural dynamics measurements. Structural Dynamics@2000: Current status and future directions, Research Studies Press, Ltd. Baldock, Hertfordshire, England, December 2000

12.Shih C., Tsuei Y., Allemang, R., Brown D.: Complex mode indication function and its applications to spatial domain parameter estimation. Proceedings of International Modal Analysis Conference VII, January 1989.

13.Uhl T.: Computer-aided identification of mechanical structure models (in Polish). WNT (Scientific Technical Publishers), Warszawa 1997.

14.Williams R., Crowley J., Vold H.: The multivariate mode indicator function in modal analysis. Proceedings of International Modal Analysis Conference III, January 1985.

15.Vold H., Schwarz B., Richardson M.: Display operating deflection shapes from non-stationary data. Sound and Vibration, June 2000.

16.Vold H., Kundrat J., Rocklin G.A.: Multi-input modal estimation algorithm for mini-computers. S.A.E. paper No. 820194, 1982.

17.Żółtowski M.: Identification of vibration hazards to building objects (in Polish). Budownictwo Ogólne (General Building), ZN ATR, Bydgoszcz 2005

18.Żółtowski M.: Measurements of acoustic properties of materials (in Polish). Diagnostyka, PTDT, Polska Akademia Nauk (Polish Academy of Sciences), vol.33, 2005 
19.Żółtowski M.: Selection of information on identification of the state of machine. UWM, Acta Academia 310, Olsztyn 2007.

20.Żółtowski M.: Computer-aided management of system's operation in production enterprise. Integrated management (in Polish). Oficyna Wydawnicza Polskiego Towarzystwa Zarządzania Produkcją (Publishing House of Polish Society on Production Management), vol. 2, Opole 2011.

21.Żółtowski M.: Modal analysis in the testing of building materials (in Polish). ITE-PIB, Radom 2011.

\section{CONTACT WITH THE AUTHOR}

Mariusz Żółtowski, Ph.D. University of Technology and Life Science in Bydgoszcz,

Ks. Kordeckiego 20, 85-225 Bydgoszcz, POLAND mazolto@utp.edu.pl 